\title{
ADVANCED TREATMENT IN RHEUMATOID ARTHRITIS. IS IT POSSIBLE TO TAPER THE BIOLOGICAL TREATMENT?
}

\author{
Ina Cambu ${ }^{1,2}$, Catalina Raluca Nuta ${ }^{1,2}$, Denisa Predeteanu ${ }^{1,2,3}$ \\ ${ }^{1}$ Sf. Maria Clinical Hospital, Bucharest, Romania \\ ${ }^{2}$ Department of Internal Medicine and Rheumatology, \\ Carol Davila University of Medicine and Pharmacy, Bucharest, Romania \\ ${ }^{3}$ Research Center of the Pathology and Treatment of Systemic Rheumatic Diseases - RCRD, Bucharest,
}

Romania

\begin{abstract}
Rheumatoid arthritis (RA) is a systemic autoimmune disease, leading to synovial hypertrophy and adjacent bone and cartilage destruction. The combined use of biological agents and methotrexate (MTX) has revolutionised the treatment of RA producing significant improvements in clinical, radiographic and functional outcomes.

The results of clinical study and experience of the specialities of rheumatology in clinical statement showed the long treatment may be associated with side effects, in addition biological treatment means high cost. The next goal should be remission without the use of biological agents.

That's why new treatment in RA means the tapering or even stopping the biological treatment in patients with RA who reached remission. In association with the new recommendation EULAR in 2013 there are many studies which showed the possibility of tapering or discontinuing the biological therapy in patients in sustained remission.
\end{abstract}

Keywords: rheumatoid arthritis, biological therapy, treatment optimization

Rheumatoid arthritis (RA) is a chronic systemic inflammatory disease with unknown etiology and autoimmune pathogenesis, characterized by progressing destructive and deformed arthropathy, but also with multiple systemic manifestations (1).

Worldwide, the annual incidence of RA is approximately 3 cases per 10,000 population and the prevalence rate is approximately $1 \%$, increasing with age and peaking between the ages of 30 and 50 years (2). Women are affected by RA approximately 3 times more often than men are, but sex differences diminish in older age groups (3).

The cause of RA remains unknown. Genetic, environmental, hormonal, immunological and infecti- ous factors are deemed to have a significant role in the occurrence of the disease. Socio-economic, psychological and lifestyle factors [eg: tobacco, which is the main environmental factor (4)] may influence the course of disease (5). There are no pathognomonic laboratory tests for the diagnosis of $\mathrm{PR}$, but the presence of anti-cyclic citrullinated peptide (anti-CCP) and rheumatoid factor (RF) is very specific for RA (6).

International recommendations for the treatment of RA include disease-modifying antirheumatic drugs (DMARDs) in association with symptomatic therapy. Classification of new DMARDs is shown in Table 1 (7).

TABLE 1. DMARDs classification (7)

\begin{tabular}{|l|l|l|}
\hline \multicolumn{2}{|l|}{ Disease-modifying antirheumatic drugs (DMARDs) } \\
\hline \multicolumn{2}{|l|}{ Synthetic DMARDs (sDMARDs) } \\
\hline $\begin{array}{l}\text { Conventional synthetic DMARDs } \\
\text { (csDMARDs) }\end{array}$ & $\begin{array}{l}\text { Targeted synthetic DMARDs } \\
\text { (tsDMARDs) }\end{array}$ & $\begin{array}{l}\text { Biological DMARDs (bDMARDs) } \\
\text { (boDMARDs) }\end{array}$ \\
\hline $\begin{array}{l}\text { Methotrexate (MTX), Leflunomide } \\
\text { (LFN), Sulfasalazine (SSZ), } \\
\text { Hydroxychlorquine(HCQ) }\end{array}$ & Tofacitinib (TFB) & $\begin{array}{l}\text { TNF-alpha Inhibitors - Infliximab (IFX), Adalimumab (ADA), } \\
\text { Etanercept (ETN), Golimumab (GLM), Certolizumab (CZ); } \\
\text { Others: Rituximab (RTX), Abatacept (ABT), Anakinra (AKR), } \\
\text { Tocilizumab (TCZ). }\end{array}$ \\
\hline
\end{tabular}

Correspondence address:

Denisa Predeteanu, MD, PhD, Department of Internal Medicine and Rheumatology, Sf. Maria Clinical Hospital,

37-39 Ion Mihalache Boulevard, District 1, Bucharest, Romania

E-mail: dpredet@yahoo.com 
DMARDs are the basic treatment since 1970. It has been shown that these drugs decrease inflammation and slow radiographic progression, but the degree to which this is accomplished is variable. The moment of DMARDs initiation has been debated, but the current consensus suggests that treatment should be started early for the overall better results of clinical improvement and prevention of erosive disease (8). The first 15 months are critical for the initiation and escalation DMARDs, in order to achieve acceptable long-term results (9).

Current guidelines recommend starting treatment with csDMARDs before adding or substituting bDMARDs (7). Importantly, the use of DMARDs in combination rather than alone is effective to achieve better clinical results and halting radiographic progression (10). csDMARDs may be combined with each other and/or with bDMARDs. Each DMARDs has its own side effects and requires strict monitoring (Table 2) (11).

Due to side effects such as severe infection and lymphoma associated with continued use of biologic therapy and the impact on the high cost of this treatment, the actual goal is the possibility of dose reduction or discontinuation of biologic therapy without periods of disease activity.

EULAR recommendations from 2013 about the therapeutic management of patients with RA argue that the patients in persistent remission after have tapered glucocorticoids can consider tapering bDMARDs, especially if treatment is combined with a csDMARDs (7).

There are multiple definitions of remission, but the most reliable are the two definitions proposed by the Committee ACR/EULAR for clinical trials (12)

Boolean definition: at any time, the patient must meet all the following criteria: the number of tender joint count $\leq 1$, the number of swollen joints $\leq 1$, Creactive protein $\leq 1 \mathrm{mg} / \mathrm{dL}$ and $\leq 1$ patient global assessment ( $0-10$ scale).

Composite index definition: at any time, the patient must have a score of DAS28 (disease activity score) $\leq 2.6$ and SDAI (simplified disease activity index) $\leq 3.3$.

In evidence-based-medicine (EBM) there are numerous studies that evaluated the decrease or discontinuation bDMARDs in patients with establish RA.

One of this study was RRR (Remision Induction by Remicade in RA). Its objective was to determine the possibility of discontinuing IFX after obtaining the low disease activity in RA patients and to evaluate the progression of joint damage during its discontinuation. This study included 114 patients from 26 centers, with RA with an average disease duration of 5.9 years who achieved and maintained low disease activity (DAS28 - Disease Activity Score $\leq 3.2$ ) for more than 24 weeks with IFX treatment. Among the 102 evaluated patients who completed the study, 56 continued to present low disease activity and 44 remained in remission (DAS28 <2.6) after one year and showed no changes in radiological damage measured by modified total Sharp score (mTSS) and functional disturbance measured by HAQ-DI (Health Assessment Questionnaire Disability Index). DAS28-ESR $\leq 2.2$ was identified as a necessary condition to obtain remission after treatment discontinuation. The study demonstrated that $71.4 \%$ of patients with deep remission (DAS28-ESR $\leq 2.2$ ) could maintain DAS28-ESR $<3.2$ while only $32.6 \%$ of the patients with $2.22<$ DAS28-ESR $<3.3$ could keep DAS28-ESR $<3.2$. These results suggest that patients with deep remission can achieve prolonged remission after the discontinuation of biological therapy (13).

In 2015 Tanaka and his colleagues published the study HONOR (Humira discontinuation Without functional and radiographic damage progression Following sustained Remission) whose objective was to investigate the possibility of discontinuing ADA for 1 year without flaring (DAS28-ESR $\geq 3.2$ ) and to identify factors enabling established patients with RA to remain ADA-free (steroid-free and sustained remission DAS28 for more than 6 months). 197 patients with inadequate response to MTX were treated with ADA + MTX. From these, 75 patients met the ADA-free criteria and were studied for 1 year. This study showed the possibility of discontinuation of ADA for 1 year in patients with stable RA. $79 \%$ of patients with deep remission did not present flare after discontinuation of ADA; a similar proportion was obtained by those who continued ADA. The characteristics of patients who could have deep remission after discontinuation ADA were: short duration of disease, low values of ESR and score DAS-28 and a long period of administration ADA. Re-administration of ADA to patients with flare during ADA discontinuation was effective (14).

In the PRESERVE study (A Prospective, Randomized Etanercept Study to Evaluate Reduced dose Etanercept + MTX v. Full dose Etanercept + MTX v. MTX alone for Effectiveness and radiographic 
TABLE 2. csDMARDs and bDMARDs in RA treatment, their targets and toxicities (11)

\begin{tabular}{|c|c|c|c|c|}
\hline Conventional DMARDs & Target & $\begin{array}{l}\text { Testing prior to starting } \\
\text { medication }\end{array}$ & Toxicities & Monitoring \\
\hline Methotrexate & $\begin{array}{l}\text { Enhances adenosine } \\
\text { release; inhibits } \\
\text { polyamines; folic acid } \\
\text { antagonist }\end{array}$ & $\begin{array}{l}\text { Creatinine, liver function } \\
\text { tests, hepatitis B and C } \\
\text { screening }\end{array}$ & $\begin{array}{l}\text { Nausea, diarrhea, liver } \\
\text { toxicity, pneumonitis, } \\
\text { cytopenias, infections, } \\
\text { lymphoma }\end{array}$ & $\begin{array}{l}\text { Liver function test, } \\
\text { creatinine, complete } \\
\text { blood count (CBC) every } \\
4-8 \text { weeks }\end{array}$ \\
\hline Leflunomide & Pyrimidine synthesis & $\begin{array}{l}\text { Creatinine, liver function } \\
\text { tests, hepatitis B and C } \\
\text { screening }\end{array}$ & $\begin{array}{l}\text { Nausea, diarrhea, liver } \\
\text { toxicity, pneumonitis } \\
\text { (rare), infections }\end{array}$ & $\begin{array}{l}\text { Liver function test, } \\
\text { creatinine, complete } \\
\text { blood count (CBC) every } \\
\text { 4-8 weeks }\end{array}$ \\
\hline Hydroxychloroquine & $\begin{array}{l}\text { TLR signaling (Toll-like } \\
\text { receptor) }\end{array}$ & Retinal screen & Retinal toxicity, nausea & $\begin{array}{l}\text { Yearly ophthalmologic } \\
\text { exam }\end{array}$ \\
\hline Sulfasalazine & $\begin{array}{l}\text { Enhances adenosine } \\
\text { pathway and inhibits } \\
\text { arachidonic acid }\end{array}$ & $\mathrm{CBC}$ & $\begin{array}{l}\text { Nausea, diarrhea, allergic } \\
\text { reactions, neutropenia } \\
\text { (rare) }\end{array}$ & $\begin{array}{l}\text { CBC every } 4-8 \text { weeks } \\
\text { during first year of } \\
\text { treatment }\end{array}$ \\
\hline \multicolumn{5}{|l|}{ Biologic DMARDs } \\
\hline Anti-TNF drugs & TNF-alpha & $\begin{array}{l}\text { Tuberculosis (TB) screen, } \\
\text { hepatitis B and C screen, } \\
\text { fungal screens (depending } \\
\text { on geography) }\end{array}$ & $\begin{array}{l}\text { Infusion and injection site } \\
\text { reactions, rash, infections, } \\
\text { lymphoma }\end{array}$ & - \\
\hline Rituximab & CD20 & $\begin{array}{l}\text { TB screen, hepatitis B } \\
\text { screen }\end{array}$ & \begin{tabular}{|l} 
Infusion reaction \\
(can be severe), \\
progressive multifocal \\
leukoencephalopathy
\end{tabular} & - \\
\hline Abatacept & $\begin{array}{l}\text { CTLA-4 CD80/86 } \\
\text { interaction }\end{array}$ & $\begin{array}{l}\text { TB screen, hepatitis B and } \\
\text { C screen, fungal screens } \\
\text { (depending on geography) }\end{array}$ & $\begin{array}{l}\text { Possible infusion reaction, } \\
\text { infections }\end{array}$ & - \\
\hline Anakinra & IL-1 receptor antagonist & TB screen, CBC & $\begin{array}{l}\text { Injection site reactions, } \\
\text { neutropenia, infections }\end{array}$ & Monthly CBC \\
\hline Tocilizumab & IL-6 receptor antagonist & $\begin{array}{l}\text { Lipid profile, CBC, TB } \\
\text { screen, hepatitis B and } \\
\text { C screen, fungal screens } \\
\text { (depending on geography) }\end{array}$ & $\begin{array}{l}\text { Neutropenia, } \\
\text { thrombocytopenia, } \\
\text { elevated total cholesterol } \\
\text { and triglycerides, bowel } \\
\text { perforations (rare), } \\
\text { infections }\end{array}$ & $\begin{array}{l}\text { Monthly CBC, creatinine, } \\
\text { cholesterol profile }\end{array}$ \\
\hline
\end{tabular}

endpoints in a moderate RA Population), patients with moderately disease activity RA despite MTX were treated with ETN $50 \mathrm{mg} /$ week and MTX for 26 weeks. 604 patients who achieved low disease activity were randomized to MTX plus ETN $50 \mathrm{mg} /$ week, $25 \mathrm{mg}$ /week or placebo. At weeks 52 after the randomization, sustained low disease activity was observed in $82.6 \%$ of patients treated with MTX plus ETN $50 \mathrm{mg} /$ week, $79.1 \%$ of those with MTX plus ETN $25 \mathrm{mg} /$ week and $42.6 \%$ of those with MTX alone (15).

In the ORION study (Outcome Orencia ${ }^{\circledR}$ Remission Induction and Navigation), ABT was discontinued in 34 RA patients (average disease duration 6.4 years) with DAS28-CRP remission after treatment with MTX plus ABT. At 52 weeks after the withdrawal, 58.8\% failed from DAS28-CRP remission (16).

In the ACT-RAY study (Adding tocilizumab or switching to tocilizumab monotherapy in metho- trexate inadequate responders: 24-Week symptomatic and structural results of a 2-year randomised controlled strategy trial in rheumatoid arthritis), 556 established RA patients (average disease duration 8.2 years) with an inadequate response to methotrexate were randomized in two groups one of which at MTX was added TCZ $8 \mathrm{mg} / \mathrm{kg}$ and another group in which was added placebo at MTX. About $50 \%$ of patients who entered into year 2 continued TCZ after achieving DAS28 $\leq 2.6$ at two consecutive visits and $86 \%$ of these patients experienced flare before the end of year 2 (17).

The favorable results of studies with decreased biological exposure or either discontinuation of therapy in patients with established RA has led to the idea of the same therapeutic approach in patients with early RA.

In the IDEA study (The Infliximab Induction Therapy in Early as rheumatoid Arthritis), patients with early RA, DMARDs naive were randomized 
into 2 groups, the group MTX plus IFX and the group MTX plus intravenous steroid as remission induction. In the first group, $24.5 \%(14 / 55)$ discontinued IFX due to sustained remission (DAS44 $<1.6$ at 6 months) and $78.6 \%(11 / 14)$ of them maintained remission for six months (18).

The OPTIMA study (Optimal Initiation Protocol for Treatment with Adalimumab and Methotrexate) was a multinational, double-blinded, randomized controlled trial, which was performed to determine the optimal protocol for treatment initiation with ADA plus MTX in RA patients. In this study, the discontinuation of ADA in patients with early RA (average disease duration 3.9 months) was also assessed. Results of ADA stopping or continuing were assessed in patients who achieved low disease activity after 26 weeks of treatment with ADA and MTX. Of the 466 patients with RA treated with ADA and MTX, 207 (44\%) achieved the stable low disease activity measured by DAS28-CRP at week 22 and 26 and they were re-randomized into 2 groups, the placebo plus MTX group and ADA plus MTX group for a period of 52 weeks. After 52 weeks the rate of remission (86\%) and the rate of low activity (91\%) were significantly higher among those who continued ADA compared to the rate of remission (66\%) rate and low activity of the disease $(81 \%)$ in those who discontinued ADA (using DAS28-CRP criteria). There were no statistically significant differences in the 2 groups in terms SDAI score (remission $62 \%$ vs. $51 \%$, low disease activity: $92 \%$ vs $84 \%$ ) and structural and functional results were comparable between the groups (19).

In the PRIZE study (The three-phase Productivity and Remission in a Randomized Controlled Trial of Etanercept vs. Standard of Care in Early Arthritis rheumatoid) patients with early RA, MTX naive with moderately disease activity were treated with MTX and ETN and remission DAS28 was achieved in $70 \%$ of patients. These patients were randomized double-blind into three groups. In one group patients received ETN at a reduced dose subcutaneously (25 $\mathrm{mg}$ ) plus MTX, in the second group patients received MTX plus placebo subcutaneously and in the third group patients received placebo oral plus placebo subcutaneously for 39 weeks. At week 39 the sustained remission was observed in $63.5 \%$ of patients with ETN plus MTX, 38.5\% with MTX plus placebo subcutaneously who discontinued ETN, and $23.1 \%$ with placebo oral plus placebo subcutaneously who discontinued ETN and MTX. There was no significant radiographic progression in any treatment group (20).

It should be mentioned that from individual studies with each of the biological agents, the studies followed with all DMARDs that showed maintenance of the clinical response and even persistent remission at decrease or discontinuation csDMARDs and/ or bDMARDs.

The RETRO study (Reduction of Therapy in Patients with rheumatoid arthritis in Ongoing remission) had intended to assess the effects of the reduction or even discontinuation of all csDMARDs (MTX, LFN, HCQ and SSZ) and/or bDMARDs (IFX ADA, ETN, GLM, CZ, TCZ) in patients with RA in stable remission. It is a multicenter, randomized study performed in 3 arms. Patients with average disease duration of 5.0 years with DAS28 $<2.6$ for at least 6 months were randomized either continuing DMARDs (arm 1), tapering DMARDs by 50\% (arm 2) or stopping DMARDs after 6 months tapering (arm 3). The primary endpoint was sustained remission during 12 months. 101 patients were analyzed. Initially, all patients fulfilled DAS28 remission and 70\% also Boolean remission. Of these, $82.2 \%$ received MTX, $40.6 \%$ bDMARDs and $9.9 \%$ other DMARDs. Overall, 67 patients $(66.3 \%)$ remained in remission for 12 months, while 34 patients (33.7\%) relapsed. The incidence of relapses was: arm 1-15.8\%, arm $2-38.9 \%$, the arm $3-51.9 \%(p=0.007)$. Multivariate logistic regression identified that the presence of anti-CCP Ab (p = 0.038) and the treatment reduction (in comparison to continuation) are predictors for relapse $(\operatorname{arm} 2: \mathrm{p}=0.012 ; \operatorname{arm} 3: \mathrm{p}=0.003)$. This study showed that more than half of RA patients in sustained remission with different treatment strategies maintained remission after tapering or discontinuation csDMARDs or bDMARDs. Relapses occurred particularly in the first 6 months after treatment reduction and were associated with the presence of anti-CCP Ab (21).

\section{CONCLUSIONS}

Biological therapy indicated in unresponsive RA to csDMARDs treatment opened new therapeutic perspectives for patients with this suffering.

The effectiveness of biologic therapy means not only reducing signs and symptoms but also the decrease of the rate of bone destruction, the increase of functionality and the improvement of capacity of work. 
Safety of biologic therapy administered in RA is proven by numerous clinical studies and it is supported by practical work where the monitoring of patients decreases the risk of side effects.

There is currently a trend of decreased exposure to biologic therapy in RA patients in order to decrease the risk of side effects and reduced costs.

\section{REFERENCES}

1. Balanescu A. Poliartrita reumatoida. In lonescu R. Esentialul in reumatologie. Bucuresti Amaltea; 2006:capitolul V: 214-250

2. Drosos A. Epidemiology of rheumatoid arthritis. Autoimmune Rev 2004; 3(Suppl 1):S20-S22.

3. Ahlmen M, Svensson B, Albertsson K, Forslind K, Hafstrom I. Influence of gender on assessments of disease activity and function in early rheumatoid arthritis in relation to radiographic joint damage. Ann Rheum Dis. 2010 Jan. 69(1):230-3.

4. Carlens C., Hergens M.P., Grunewald J., et al. Smoking, use of moist snuff, and risk of chronic inflammatory diseases. Am J Respir Crit Care Med. 2010 Jun 1. 181(11):1217-22.

5. Brasington R.D. Jr. Clinical features of rheumatoid arthritis. In: Hochberg MC, Silman AJ, Smolen JS, et al, eds. Rheumatology. 5th ed. Philadelphia: Mosby; 2011: chapter 6: 629-638.

6. Tehlirian C.V., Bathon J.M. Rheumatoid arthritis. A. Clinical and Laboratory manifestations. In: Klippel JH. Primer on the Rheumatic Disease, thirteenth edition. New York: Sprienger Science + Business Media 2008: chapter 6: 114-121.

7. Smolen J.S., Landewe R., Breedveld F.C., et al. EULAR recommendations for the management of rheumatoid arthritis with synthetic and biological disease-modifying antirheumatic drugs: 2013 update. Ann Rheum Dis. 2014 Mar. 73(3):492-509.

8. Verstappen S.M.M., Jacobs J.W.G., Bijlsma J.W.J., et al. Fiveyear followup of rheumatoid arthritis patients after early treatment with disease-modifying antirheumatic drugs versus treatment according to the pyramid approach in the first year. Arthritis \& Rheumatism. 2003; 48:1797

9. Weng H.H., Ranganath V.K., Khanna D., et al. Equivalent Responses to Disease-modifying Antirheumatic Drugs Initiated at Any Time During the First 15 Months After Symptom Onset in Patients with Seropositive Rheumatoid Arthritis. The Journal of Rheumatology. 2010; 37

10. Ma M.H.Y., Kingsley G.H., Scott D.L. A systematic comparison of combination DMARD therapy and tumour necrosis inhibitor therapy with methotrexate in patients with early rheumatoid arthritis. Rheumatology. 2010; 49:91

11. Kahlenberg J.M., Fox D.A. Advances in the medical treatment of rheumatoid arthritis. Hand Clin. 2011 Feb; 27(1): 11-20

12. Felson D.T., Smolen J.S., Wells G., et al. American College of Rheumatology/European League against Rheumatism provisional definition of remission in rheumatoid arthritis for clinical trials. Ann Rheum Dis 2011;70:404-13. doi:10.1136/ard.2011.149765

13. Tanaka Y., Takeuchi T., Mimori T., et al. RRR study investigators. Discontinuation of infliximab after attaining low disease activity in
Multiple studies with biological agents confirm the maintenance of total remission at decreased exposure to biological treatments and even their discontinuation.

EULAR recommendations and national guidelines for biologic therapy in RA support the idea of "tapering" and even stoping of biological therapy in patients with this condition.

patients with rheumatoid arthritis: RRR (remission induction by Remicade in RA) study. Ann Rheum Dis 2010;69:1286-91.

14. Tanaka Y., Hirata S., Kubo S., et al. Discontinuation of adalimumab after achieving remission in patient with established rheumatoid arthritis: 1-year outcome of HONOR study. Ann Rheum Dis 2015; 74:389-395 doi:10.1136/annrheumdis-2013-204016

15. Smolen J.S., Nash P., Durez P., et al. Maintenance, reduction, or withdrawa of etanercept after treatment with etanercept and metrotrexate in patients with moderate rheumatoid arthritis (PRESERVE): a randomized controlled trial. Lancet. 2013 Mar 16; 381(9870):918-29. doi: 10.1016/S0140-6736(12)61811-X. Epub 2013 Jan 17.

16. Matsubara T., Ohta S., Mukai M. et al. ORION study group: Abatacept biologicfree remission study in established rheumatoid arthritis patients ORION study. Ann Rheum Dis 2013; 72 (Suppl. 3): 613

17. Dougados M., Kissel K., Sheeran T., et al. Adding tocilizumab or switching to tocilizumab monotherapy in methotrexate inadequate responders: 24-week symptomatic and structural results of a 2-year randomised controlled strategy trial in rheumatoid arthritis (ACTRAY). Ann Rheum Dis doi:10.1136/annrheumdis-2011-201282

18. Nam J.L., Villeneuve E., Hensor E.M., Conaghan P.G., Keen H.I., Buch M.H., et al. Remission induction comparing infliximab and high-dose intravenous steroid, followed by treat-totarget: a double-blind, randomised, controlled trial in new-onset, treatment- naive, rheumatoid arthritis (the IDEA study). Ann Rheum Dis. 2014; 73(1):75-85.

19. Smolen J.S., Emery P., Fleischmann R., et al. Adjustment of therapy in rheumatoid arthritis on the basis of achievement of stable low disease activity with adalimumab plus methotrexate or methotrexate alone: the randomized controlled OPTIMA trial. Lancet 2013. Epub ahead of print. doi:pii: S0140-6736(13)61751-1. 10.1016/S0140-6736(13)61751-1

20. Emery P., Hammoudeh M., FitzGerald O., Combe B., Martin Mola E., Bukowski J., et al. Assessing maintanance of remission with reduced dose etanercept plus methorexate, methotrexate alone, or placebo in patients with eary rheumatoid arthritis who achieved remission with etanercept and methotrexate: The PRIZE study [abstract]. Ann Rheum Dis. 2013; 72(Suppl 3):399.

21. Haschka J., Englbrecht M., Hueber A., et al. Relapse rates in patients with rheumatoid arthritis in stable remission tapering or stopping antirheumatic therapy: interim results from the prospective randomized controlled RETRO study. Ann Rheum Dis doi:10.1136/ annrheumdis-2014-206439 